\title{
Migración en Colombia: factores psicosociales y vínculos transnacionales
}

\author{
Migration in Colombia: psychosocial factors and \\ transnational links
}

\section{Migraçao em Colombia: fatores psicosociais e vinculos transnacionais}

\section{Gloria Amparo Giraldo Zuluaga* - Myriam Salazar

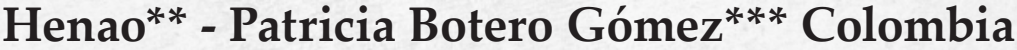

\author{
Recibido el 9 de febrero de 2012, aceptado el 8 de mayo de 2012
}

\section{Resumen}

Objetivo: identificar y analizar las narrativas de los migrantes y sus familiares en torno a su experiencia transnacional. Metodología: partiendo de un enfoque mixto de investigación (cuantitativo y cualitativo), se realizaron encuestas y entrevistas a los (las) migrantes y sus familias. Posteriormente, desde una perspectiva que privilegia los "discursos" y la "subjetividad" de los actores, se hizo un acercamiento comprensivo a sus narrativas a fin de interpretar sus saberes, experiencias y percepciones. Las categorías de análisis fueron las características psicosociales y vínculos familiares. La razón para esta prelación temática es que en el estado del arte se identificaron vacíos en lo relacionado con el análisis de las vivencias, experiencias y mundo subjetivo de los protagonistas del fenómeno migratorio. Resultados: dentro de las principales "características

Artículo de investigación que surge a partir de una investigación a mayor escala "Narrativas de migración: Calidad de vida, caracterización Psicosocial y vínculos familiares de familias con padres en situación de migración y en éxodo del Eje Cafetero". Fecha de realización: Noviembre de 2010 Diciembre 2011, financiada por la Universidad de Manizales.

* Magister en Educación. Licenciada en Filosofía y Letras. Docente investigadora de la Universidad de Manizales (Colombia).gloriamparogz@gmail.com

** Doctora en Ciencias Sociales niñez y Juventud. Magíster en Ciencias de la Educación. Psicóloga. Docente investigadora de la Universidad de Manizales y del Centro de Estudios Avanzados en Niñez y Juventud (Colombia).myriam@umanizales.edu.co.

*** Doctora en Ciencias Sociales niñez y juventud. Magíster en Educación y desarrollo comunitario. Psicóloga. Docente Investigadora Universidad de Manizales (Colombia). jantosib@gmail.com 
psicosociales", se pudo profundizar en temas como motivaciones para emigrar, redes de apoyo, riesgos, temores, sentimientos y emociones. Respecto a los "vínculos familiares", fue posible establecer sus principales cambios, afectaciones, redistribuciones del poder, novedades, tensiones y consecuencias. Conclusiones: predominan las ambivalencias, tanto en los propósitos como en las transferencias y desplazamientos de sentidos y emociones. Las respuestas oscilan entre la idealización máxima del proceso migratorio y la comprensión realista y dramática de sus efectos. No solamente se modifican las estructuras y relaciones familiares sino que su percepción se hace más positiva con el tiempo y el logro de los objetivos propuestos. Se confirma, como lo sugerían estudios previos, la visión "pragmática" y positiva que manifiestan los implicados en el fenómeno, a pesar de las interpretaciones negativas tradicionales.

Palabras claves: migración, relaciones familiares, vínculos, factores psicosociales.

\begin{abstract}
Objective: To identify and analyze the narratives of Colombian migrants and their relatives regarding their transnational experience. Methodology: a qualitative and quantitative research method (mixed approach) was used. Surveys and interviews were conducted with migrants and their relatives. Subsequently, from a perspective that privileges the "discourse" and "subjectivity" of the participants, a comprehensive approach to their narratives was carried out in order to interpret their knowledge, experiences and perceptions. The categories of analysis were psychosocial characteristics and family ties. The reason for the priority of this subject matter is the lack of analysis found in the state of the art with respect to life, experiences and the subjective world of the participants in the migration phenomenon. Results: Within the main "psychosocial characteristics", a deeper insight was gained into topics such as motivation to migrate, support networks, risks, fears, feelings and emotions. Regarding "family ties", it was possible to establish the main changes, disruptions, redistributions of power, new occurrences, tensions and consequences. Conclusions: Ambivalences regarding both the purposes and the transfers and changes in feelings and emotions prevail. Answers range from maximum idealization of the migration process to understanding its realistic and dramatic effects. Not only do the participants' family structures and relationships change but their perception also becomes more positive over time and with the achievement of their proposed objectives. The "pragmatic" and positive perspective that participants showed about this phenomenon has been reconfirmed as in other studies, despite the traditionally negative interpretations
\end{abstract}

52 Keywords: migration, family relationships, family ties, psychosocial factors 


\section{Resumo}

Objetivo: identificar e analisar as narrativas dos migrantes e seus familiares em torno a sua experiência transnacional. Metodologia: partindo dum enfoque misto de pesquisa (quantitativo e qualitativo), realizaram se enquetes e entrevistas aos (as) migrantes e suas famílias. Posteriormente, desde a perspectiva que privilegia os "discursos" e a "subjetividade" dos atores, se fez um aproxima mento compreensivo a suas narrativas a fim de interpretar seus saberes, experiências e percepções. As categorias de analise foram às características psicossociais e vínculos familiares. A razão para esta prelação temática é que no estado da arte se identificaram vazios no relacionado com o analise das vivencias, experiências e mundo subjetivo dos protagonistas do fenômeno migratório. Resultados: dentro das principiais "características psicossociais", pôde aprofundar em temas como motivações para emigrar, redes de apoio, riscos, temores, sentimentos e emoções. Respeito aos "vínculos familiares" foi possível estabelecer seus principais câmbios, afetações, redistribuições do poder, novidades, tensões e consequências. Conclusões: Predominam as ambivalências, tanto nos propósitos como nas transferências e deslocamentos de sentidos e emoções. As respostas oscilam entre a idealização máxima do processo migratório e a compreensão realista e dramática de seus efeitos. Não somente se modificam as estruturas e as relações familiares pelo contrario se faz mais positiva com o tempo e o logro dos objetivos propostos. Confirma se, como o sugeriam estudos prévios, a visão "pragmática" e positiva que manifestam os implicados no fenômeno, a pesar das interpretações negativas tradicionais.

Palavras chaves: migração, relações familiares, vínculos, fatores psicossociais.

Para $\mid$ Giraldo Z., G. A.; Salazar H., M.; Botero G. P. (julio - diciembre 2012). Migración en 


\section{Introducción}

La migración es un fenómeno sociocultural creciente en las sociedades actuales y uno de los mayores desafíos políticos que enfrenta la región del Eje Cafetero en Colombia. Por un lado, devela las contradicciones y el grado desigual de desarrollo de las sociedades que entran en contacto (la expulsora y la receptora). Por otro, implica la irrupción de nuevos problemas sociales, legales y culturales, para los cuales buena parte de las políticas públicas tradicionales no estaban preparadas. La migración contemporánea plantea nuevos desafíos de integración social y de tolerancia cultural en un mundo globalizado, crecientemente competitivo y problemático. Esto significa que la familia, y en particular sus miembros, viven una situación de alta vulnerabilidad, es decir, un aumento de los riesgos y de la posibilidad de que sus derechos se vean vulnerados o su integridad afectada. En este contexto, es urgente conseguir una mejor comprensión de este fenómeno haciendo uso de una herramienta recientemente reconocida: la propia percepción de los migrantes y sus familias, así como el análisis del mundo subjetivo en que viven y de sus posibles transformaciones.

\section{Referentes teóricos}

El fenómeno de la migración se ha estudiado desde diversos referentes teóricos: el económico (Borjas, Todaro y Maruszko), el individualista (Prada, Actis y Pereda) y el estructuralista (Hurtado).

Desde la perspectiva estructuralista, se describe la migración familiar como una "nueva economía de la migración” (Hurtado, 2007). Su unidad de análisis no es el individuo como en la economía tradicional, sino la familia.

Según Actis, Pereda y Prada (2000), frente al fenómeno se requiere el análisis de todos los vínculos existentes entre los polos económico, cultural y políticos. Además, postulan que los movimientos migratorios sólo pueden ser comprendidos en el contexto de un análisis histórico que identifique las principales transformaciones en una sociedad concreta. En otros términos, no se acepta la existencia de "leyes universales" que expliquen las migraciones; por el contrario, cada período histórico da lugar a condiciones estructurales específicas, que requieren instrumentos conceptuales adecuados.

Al respecto la OIM (2004), plantea que la migración internacional es también el resultado de los cambios reproducidos con la 'globalización', en especial las interacciones entre culturas, religiones y etnias, en el contexto de una ampliación y penetración de relaciones capitalistas en sociedades cada vez más disímiles.

La perspectiva 'transnacionalista', enfoque propio de estudiosos latinoamericanos como Garay y Medina (2008), aborda la migración como un movimiento realizado 54 por "personas" que, al migrar lo hacen con toda su historia propia, cultural y social y 
que construyen un vivir "transnacional" que permite mantener los vínculos entre los países, incluyendo su lengua y su vida familiar.

De otro lado, se sabe que los diversos espacios sociales, como el familiar y el comunitario (pero también el nacional y el regional), han sufrido importantes modificaciones, entre las comunidades emisoras y las sociedades receptoras, y esto se expresa en el establecimiento de nuevos vínculos y procesos socio-culturales (CLACSO, 2010).

Es por esto que nuestra perspectiva de trabajo, al centrar su interés en el estudio detallado de las "narrativas" de los miembros de la familia transnacional, ha retomado las claves de interpretación propuestas por Daiutte y Lightfoot (2004) y Daiute y Botero (2011), en las cuales las narrativas y otros discursos se constituyen en medios materiales y simbólicos que ilustran los cambios sociales.

Por cierto las "narrativas", como formas de estudio e interpretación de la realidad social, son utilizadas a fondo en un trabajo modelo de las investigadoras colombianas Puyana, Motoa y Viviel (2009). En dicho estudio, que ha sido referente internacional, se afirma que las migraciones involucran, además de los componentes económicos y sociales conocidos, factores de orden colectivo tales como las redes familiares, los vínculos afectivos y la comunicación inter-familiar. De aquí que la metodología asumida por ellas, y de la que este estudio toma algunos procedimientos, parece de singular relevancia no sólo porque es novedosa sino integral y, además de la caracterización objetiva del fenómeno transnacional, hace hincapié en las subjetividades de las (los) protagonistas.

\section{Metodología}

La investigación abordó el análisis y la comprensión de las narrativas de migrantes desde dos dimensiones: una objetiva y otra subjetiva. La dimensión objetiva correspondió a la caracterización socio-demográfica y al estudio de los factores que determinaban la calidad de vida de las familias participantes. La dimensión subjetiva se interesó en las vivencias y percepciones de las familias a partir del estudio de las "narrativas" de padres, madres, niños, jóvenes y cuidadores.

El procedimiento metodológico se desarrolló en dos momentos: el cuantitativo y el cualitativo. En el estadio cuantitativo se realizaron 38 encuestas que se tabularon mediante el software SPSS. En el estadio cualitativo se partió de una perspectiva comprensiva hermenéutica para cotejar y analizar las narrativas recolectadas. De las narrativas básicas, debidamente transcritas, se privilegiaron los fragmentos alusivos a saberes, vivencias y percepciones de los procesos migratorios y se elaboraron matrices de comprensión para organizar la información.

Para citar este artículo:
Giraldo Z., G. A.; Salazar H., M.; Botero G. P. (julio - diciembre 2012). Migración en Colombia: factores psicosociales y vínculos transnacionales. Ánfora, 19 (33), 51 - 69. Universidad Autónoma de Manizales. ISSN 0121-6538. 


\section{Resultados}

\section{Migración en el Eje Cafetero: factores psicosociales y vínculos transnacionales}

\section{Factores psicosociales en la migración}

\section{Motivaciones para emigrar}

Al estudiar en detalle las narrativas recolectadas, se encuentra que los argumentos y motivaciones de los emigrantes son recurrentes: la mala situación económica en Colombia, el deseo de sacar adelante los hijos (especialmente los más pequeños) y las expectativas y sueños de nuevas oportunidades y de alcanzar un mejor futuro en el lugar de destino.

Respecto al primer argumento (la difícil situación económica) las narrativas y testimonios son contundentes:

"Me vine por lo económico, o sea, mis hijos, para que ellos estuvieran bien porque la situación era muy dura" (Mujer, 28 años).

"Viajé por el desempleo, no estaba haciendo nada y tenía unos compromisos con mi familia, estaba desesperado y fue la única alternativa" (Hombre, 41 años).

Después de las motivaciones de tipo económico o laboral, un elevado porcentaje de emigrantes justifica su salida con base en las expectativas y esperanzas de un mejor porvenir en el exterior. Como se sabe, el sueño común de muchos latinoamericanos sigue siendo vivir y trabajar en el extranjero, pues piensan que la vida es mejor y más próspera en Estados Unidos o en Europa.

"A mi esposo un amigo que estaba allá le dijo que nos fuéramos por que las cosas allá eran mejor" (Mujer, 48 años)

Respecto a este "sueño migratorio", tan enraizado en muchos imaginarios sociales y familiares de este país, algunos autores lo consideran una especie de "contagio social" (Pesantez, 2006), en el sentido de que estas motivaciones tienen una gran carga simbólica y arrastran e incitan a los familiares y amigos de los emigrantes.

En menor proporción, se destacan y señalan otros motivos para la migración. Muchas mujeres, por ejemplo, suelen emigrar para resolver asuntos de tipo conyugal o personal y para escapar a las múltiples violencias que se ejercen sobre ellas en nuestro medio.

"Viajé porque mi esposo me pegaba y me trataba muy mal y tenía que escaparme de esa situación, no resistía seguir con esa vida" (Mujer, 35 años). 
Finalmente no faltaron las motivaciones forzosas, generalmente vinculadas al desplazamiento como consecuencia del conflicto y de la violencia consecuente.

“En el pueblo, cuando llegó la guerrilla, nos decían que los que no los ayudaran a ellos los mataban. Entonces mi marido me dijo que por que no nos íbamos.” (Mujer, 40 años).

\section{Redes de apoyo}

El apoyo que reciben los emigrantes comienza a ser de interés para los estudios sobre este tema. En primer lugar, porque refiere la creación o existencia de redes que propician la migración. Y, en segundo lugar, porque el apoyo de familiares o amigos representa una razón fundamental, una motivación de fondo en el proceso (Puyana, Motoa y Viviel, 2009, p.93).

En este estudio se encuentra que hay dos tipos de apoyo de gran valor: el de los propios familiares (en términos económicos y morales) y el de los amigos o "conocidos" en el extranjero.

"Cuando comenzamos a hacer los trámites una amiga me dijo que ella también se iría. Además como allá ya estaba mi cuñado y la familia era mas fácil todo. (...) Yo llamé a mi mamá para que me ayudara en todo lo del viaje. Ella me regaló una plata y con eso compramos los pasajes. Después una hermana me regaló otra plata. Mucha gente me ayudo económicamente" (Mujer, 56 años).

En relación con el apoyo que brindan ciertas personas vinculadas a las instituciones de migración (sin que sepamos a ciencia cierta si se trata de redes legales o ilegales) una emigrante nos manifestó:

"Conseguimos los pasajes y los papeles fueron fáciles de sacar debido a que un primo mío trabaja en la embajada” (Mujer, 48 años).

\section{Riesgos y temores}

En la medida en que el proyecto migratorio tiene unas motivaciones y unos objetivos muy claros, la mayor parte de los temores de quienes emigran tiene que ver con alcanzar dichos objetivos o fracasar.

"No sé, llegar allá y no sentirme bien, llegar sin trabajo, no conseguir trabajo, que de pronto la gente lo tratara mal a uno y dejar a mis hijos acá y no saber que les iba a pasar" (Mujer,28 años).

Otros entrevistados consideran que el mayor riesgo -y de allí su mayor temor- estaba relacionado con la pérdida de la familia, el distanciamiento o la disminución de los afectos primordiales.

"No volver a ver a mi hijo y a mi familia, tal vez no pasar y quedar llena de deudas" (Mujer, 46 años).

Para citar este artículo:
Giraldo Z., G. A.; Salazar H., M.; Botero G. P. (julio - diciembre 2012). Migración en Colombia: factores psicosociales y vínculos transnacionales. Ánfora, 19 (33), 51 - 69. Universidad Autónoma de Manizales. ISSN 0121-6538. 


\section{Sentimientos y emociones}

Este estudio también indagó sobre el tipo de sentimientos y emociones que se producen al momento de abandonar la familia y qué repercusiones tienen sobre el emigrante y sobre el grupo familiar. En un primer momento los sentimientos son de dolor, de abandono y de sacrificio:

"Es un sentimiento que no se puede describir; lo único es que uno se siente morir lentamente" (Mujer, 28 años).

Son bastante ambiguos los sentimientos del emigrante. Por un lado hay una sensación de dolor profundo al dejar la familia y, en especial, a los hijos. Pero, por otro lado, se sobrepone un sentimiento positivo (casi que una especie de alegría), derivado del proyecto migratorio, y que es el sueño de alcanzar un propósito superior y, como tal, una meta que justifica cualquier sufrimiento: "Sentía una tristeza grandísima por dejar a mis hijos, pero una felicidad porque sentía que podía conseguir muchas cosas" (Mujer, 28 años).

Quizá por esto es que se dice que el proyecto de migración no es individual (como se pensaba hace muchos años) sino que tiende a planificarse y a resolverse como resultado de una ilusión colectiva previa, de un "proyecto familiar" que justifica al emigrante ante sí mismo, ante los suyos y ante la sociedad (López y Loaiza, 2009, p.845).

\section{Cambios que se dieron después de la migración}

\section{Vínculos familiares}

Los vínculos afectivos sufren las consecuencias del proceso migratorio. De la manera como se responda a esos cambios depende en buena medida el éxito o el fracaso del proyecto de familia transnacional.

Muchos se niegan a aceptar los cambios aduciendo el logro de las metas establecidas.

"No, porque les ayudo económicamente y ellos me están agradecidos" (Hombre, 41 años).

Otros, consideran los aspectos negativos de la migración y entre ellos la distancia y la pérdida de la confianza:

"Sí. La familia se ha distanciado y ya no me hacen falta" (Mujer, 32 años). "Sí, porque al estar más distante se pierde la confianza" (Mujer, 25 años).

Sin duda, una de las características fundamentales de la familia transnacional es la transformación inevitable, aunque consciente, de los vínculos familiares, pues con la emigración las familias "tienen que amoldarse a nuevos arreglos que les permiten mantener o recomponer sus relaciones de pareja, interactuar de diferente modo entre padres, madres, hijos e hijas, hermanos, hermanas y otros parientes, así como en las funciones del cuidado que comprenden la autoridad, la protección y el trabajo doméstico" (Puyana, et al., p. 181). 


\section{Distancias y desapegos}

Se ha podido establecer que los cambios más importantes en las relaciones familiares se producen en cuatro áreas básicas: el cuidado de los hijos, las obligaciones domésticas, la gestión y manejo de los recursos económicos y los procesos de toma de decisiones (González y Restrepo, 2010).

En el primer caso, y a manera de ejemplo, se señala que, como consecuencia de la cada vez más elevada migración femenina, se ha producido un fenómeno que era impensable en la cultura machista y que consiste en la necesidad de que "los compañeros, y en algunos casos sus hijos, asuman parte de las tareas domésticas” (Gil, 2010, p. 88).

En lo relativo al cuidado de los hijos, este estudio corrobora que los emigrantes y sus familias tienen que llegar a unos muy concretos -aunque complejos- acuerdos internos para el mantenimiento, manejo y protección de los hijos. Acuerdos que, no obstante, no garantizan siempre el mantenimiento de la unidad familiar y que no están exentos de ciertas consecuencias indeseables. Quizá la más mencionada, a lo largo de las entrevistas, fue la del "enfriamiento" o "distanciamiento" de las relaciones. Esto es lo que expresaron al respecto las y los emigrantes:

"Todo, todo, todo fue diferente porque ya no hablaba tan frecuente con mi familia, (...) Una está más concentrada en trabajar y en los planes que tiene, en los proyectos" (Mujer, 46 años).

"La relación con mis hijos se enfrió mucho, mucho. (...) Pues yo los llamaba para verme con ellos por el internet y ya a lo último no se conectaban; se conectaban solamente cuando necesitaban dinero, nada más. Entonces eso me puso muy triste" (Mujer, 28 años).

A pesar de esta secuela, común a todas las familias transnacionales, se puede apreciar en los testimonios obtenidos una percepción de fortalecimiento de las relaciones familiares, como consecuencia precisamente de la distancia y del sueño migratorio

"Ha mejorado con la mayoría de familiares, la distancia nos ha ayudado a valorarnos más. En lo familiar se ha fortalecido la comprensión y la amabilidad” (Mujer, 25 años).

En el lado opuesto, se hallaron también testimonios concretos del "desastre" personal, familiar y social, que representa la migración, a pesar de que se mantiene el vínculo y, con él, la modalidad de familia transnacional. Una emigrante confesó:

"Se me acabó mi hogar, y eso ha sido terrible. Han pasado 4 años y aún me duele, pero él ya tiene otra familia. Y con los demás; mi madre y mis hermanos, piensan que yo estoy tapada de plata y me piden dinero. Es triste pero eso represento para ellos. (Mujer, 42 años).

Por otra parte, una gran mayoría de padres migrantes (especialmente las mujeres) siguen lamentando la imposibilidad de participar activamente en la crianza de los hijos que dejaron en el país. 
"Dificultades para comunicarme con mi hijo, porque no me permitían hacerlo. Lo lloraba todos los días y aun lo hago, ya que mi hijo es lo que más amo en esta vida. Cada día perdiéndome de él, de verlo crecer, de darle su comida, de bañarlo etc."(Mujer, 27 años).

Desde lo psicosocial esta sensación de culpa puede transformarse, sin el duelo respectivo, en un lastre emocional de enormes repercusiones. Y, desde luego, este ha sido por años el tema preferido por los medios de comunicación para culpar -erróneamente- a las madres emigrantes "pues derivan de la migración problemas de los niños y niñas, con todo tipo de acusaciones que finalizan con el juicio condenatorio hacia la migración materna, ya que se considera que así se desintegra la familia" (Puyana, et al., 2009, p. 126).

\section{No todo resultó como pensaba}

Si la vida familiar se ve profundamente afectada por la migración, es posible presumir que se producirán cambios profundos en la vida personal de los emigrantes.

"Aquí uno pierde la libertad porque se siente preso de no poder hacer libremente las cosas que uno quiere. Y también se pierde la familia porque pasan los años y no los volvemos a ver" (Mujer, 30 años).

Por supuesto que la migración contempla el alto riesgo de que se acabe o deteriore paulatinamente la relación de pareja y esto mantiene en tensión los vínculos entre el emigrante y su pareja.

"La relación entre los dos se fue enfriando mucho. No es lo mismo por teléfono que tener la persona acá. Pero igual, el siempre me respondía económicamente con lo que tenía que mandar". (Mujer, 28 años).

No obstante las percepciones mencionadas subsiste en muchas personas la sensación de que los cambios fruto de la migración implican, en el fondo, un cambio de actitud y una valoración distinta de la vida.

"Ya valoro más las cosas. Antes todo me importaba nada y ahora a cualquier cosa hay que darle mucho significado" (Mujer, 28 años).

\section{Redistribución del poder luego de la migración}

Las repercusiones de la migración en las relaciones familiares son más complejas y difíciles cuando se refieren al reordenamiento del poder y al manejo de la autoridad al interior del grupo familiar. Si a esto se le suma la importancia que tiene el dinero en los asuntos de familia, se encuentra que quien maneja dichos recursos es quien termina asumiendo la autoridad y el poder familiar. Por esto Castro (2007) asegura "el hecho de ser proveedores confiere mayores posibilidades de mando y autonomía hasta el punto de considerar que son quienes deben dar la 'última palabra' en las decisiones importantes con respecto al hogar y la familia" (p. 77).

Para citar este artículo:
Giraldo Z., G. A.; Salazar H., M.; Botero G. P. (julio - diciembre 2012). Migración en Colombia: factores psicosociales y vínculos transnacionales. Ánfora, 19 (33), 51 - 69. Universidad Autónoma de Manizales. ISSN 0121-6538. 
"Pues en la casa antes el poder lo tenía yo, y hasta por eso mi hermana me criticaba. Pero ahora ese poder pasó a manos de otra hermana por que yo a ella es a quién le mando la plata con la que sobreviven" (Mujer, 56 años).

"Pues el poder siempre lo he tenido yo. Sin embargo, y de acuerdo a todo, mi hija lleva el control, ya que ella es quien me sostiene" (Mujer, 62 años).

Claramente son cruciales las afectaciones, tanto positivas como negativas, que una perspectiva de género introduce en esta materia. Como sugieren muchas otras investigaciones, entre ellas la de Pedone et al. (2010) y Castro (2007), la emigración de la mujer afecta de inmediato el ejercicio de la maternidad, la estructura del grupo familiar, las relaciones conyugales y las prácticas de crianza.

En esta dirección algunos autores (Puyana, et al., 2009) sostienen que el cuidado de los hijos no se discute o negocia demasiado, pues la persona que queda en Colombia es quien se encarga de la crianza.

A pesar de lo anterior, y de los cambios que traen las nuevas exigencias de la globalización y los procesos migratorios, todavía hay personas (en especial hombres) que se aferran a estereotipos tradicionales:

"En mi familia el poder siempre lo he mantenido yo, así esté acá (en España)" (Hombre, 45 años).

\section{Vínculos y relaciones familiares}

\section{Desconsolados pero contentos}

Complejas y variadas son las actitudes y reacciones de los familiares ante la emigración de uno de los suyos. Las primeras manifestaciones (así como el relato que evoca ese momento) son de tristeza, dolor, desesperación y angustia. Las personas mayores (padres y madres) son quienes sufren más este momento:

“Cuando el avión despegó, sentí que el corazón me dejó de latir. Pero mi esposo fue y me recogió y me dijo que estuviera tranquila, que todo iba a salir a las mil maravillas" (Mujer, 50 años).

Desde luego que, como se dijo antes, el hecho de compartir las justificaciones del emigrante (en lo que respecta al viaje y a los sueños colectivos de progreso) hace que los sentimientos cambien rápidamente del dolor a la alegría y de la incertidumbre a la esperanza:

"Yo estuve desconsolado pero a la vez muy contento; porque ella lo que se propuso lo consiguió. Es una mujer muy verraca y echada pa' lante” (Hombre, 46 años).

\section{Cambios después de la Migración}

La familia de origen no solamente es la primera red de ayuda, el principal soporte de la emigración, sino que, además, tiene una enorme importancia en los acontecimientos 
posteriores y en la consolidación del proyecto transnacional. Autores como López y Loaiza (2009) , afirman que esta "red parental extensa" contribuye al proceso migratorio en tanto "da el soporte emocional necesario a sus hijos e hijas, ante la incertidumbre que genera la emigración" (p. 855). Por eso no es extraño que la mayoría de las percepciones familiares posteriores a la migración sean optimistas y recalquen los valores derivados de esa experiencia: auto-estima, ayuda mutua, solidaridad.

"Mi vida cambió desde que mis princesas se fueron. Pero me han dado fuerza para enfrentar la vida y los problemas" (Mujer, 50 años).

"He aprendido a sobrellevar la soledad, la ausencia de las personas que mas se quiere y a valorar cada momento de la vida" (Mujer, 50 años).

La "cuidadora" o el "cuidador", es decir, la persona que queda a cargo de la familia en Colombia, se convierte en la principal figura de autoridad. Y a pesar de que los cuidadores son quienes sufren el rigor de esta nueva situación, sus manifestaciones son de aceptación positiva e incluyen la confirmación de valores compartidos con el emigrante: como la responsabilidad, la tolerancia, la reconciliación y el agradecimiento.

\section{Tensiones con el proceso migratorio}

Aparte de los sentimientos ambiguos reseñados con anterioridad y del esfuerzo -apenas natural- por mantener y desarrollar la vida como antes, hallamos que las principales tensiones y enfrentamientos se relacionan con el manejo de los recursos económicos y la incertidumbre (la inestabilidad) que deriva en el "miedo" por el porvenir y el "temor" que produce aceptar las nuevas relaciones de autoridad, tanto para quien las ejerce como para quien las sufre.

"Bueno, yo creo que dos. Una es que la gente cree que uno todo se lo puede resolver mandándoles la plata que ellos necesitan; entonces las relaciones a veces se ponen pesadas. Y otra es de miedo o de abandono" (Mujer, 56 años).

"De pronto puede ser la inestabilidad, por que las personas que se quedan ya comienzan a hacer su vida como a ellos mejor les parece" (Mujer, 40 años).

Estas percepciones y estos sentimientos, en muchos casos contradictorios, desencadenan ambivalencias (tensiones y dualidades) muy diversas en las relaciones afectivas con el emigrante. Muchos investigadores, como Puyana et al. (2009), sugieren que esto conduce a inevitables "ocultamientos" en la comunicación y a que ambos lados de la relación (emigrantes y familiares) se reinventen las experiencias y sentimientos e, incluso, atenúen y negocien las tensiones existentes, con el propósito de hacer feliz al otro y mantener el sueño migratorio.

\section{Consecuencias de la migración}

La mayoría de investigaciones y especialistas consultados, concuerdan en que los emigrantes y sus familias perciben el proyecto migratorio como algo positivo. A pe- 
sar de las grandes dificultades, penurias, obstáculos y dramas vividos, los emigrantes defienden a como dé lugar su proyecto e incluso lo justifican mucho tiempo después de realizado.

Gil (2010) por ejemplo, destaca que en sus investigaciones no es frecuente el "discurso victimista" y que aunque haya críticas, reclamos y reivindicaciones, no se encuentra "ningún lamento por el desarraigo o la desculturización, sino una mirada pragmática, que cuenta la migración como experiencia de cambio y aprendizaje" (p. 90). Esto hace que las narrativas sobre migración tengan, en general, un carácter realista y equilibrado:

\section{Significados de vivir en otro país}

Cuando se indaga por la experiencia concreta del emigrante al comenzar otra vida en un país diferente, se encontró que las respuestas incluyen percepciones que van desde la noción de abandono y traslado hasta los imaginarios simbólicos de horizontes, cometas y puertas que hay que cruzar para alcanzar lo que se quiere.

"Significa dejar a los que te han visto crecer, significa dejar todo lo que construiste en tu país. Es coger tus sueños y trasladarlos a otra parte, en la que ellos mismos se construyen a la par con tu supervivencia" (Mujer, 36 años).

"Significa explorar y encontrar otros horizontes, es arriesgar todo lo que tienes, par ver si ganas más” (Mujer, 56 años).

"Es como una puerta que se abre y que cada quien tiene que sostener para que no se cierre" (Mujer, 40 años).

\section{Lo que más extrañan}

En cuanto a las personas, objetos, asuntos y memorias que los emigrantes más extrañan, este estudio halló que son más bien de tipo general (no suelen precisarse con detalle) y, por supuesto, mencionan la familia como eje central y enseguida el país o la zona de donde se partió.

"A mi familia,... a mi pueblo y a toda su gente" (Mujer, 48 años). "La tierrita y todas las cosas" (Hombre, 45 años).

Las opiniones, en cambio, se muestran bastante divididas respecto al lugar donde se siente mejor el emigrante. Sin duda que esta percepción está asociada al tiempo de permanencia fuera del país y a la duración misma del proyecto migratorio. Se considera, por lo visto hasta el momento, que, a medida que pasa el tiempo, aumenta la conformidad del emigrante con su lugar de destino.

"En mi país, porque es de donde realmente soy y lo tengo todo" (Mujer, 36 años). "Obviamente que acá" (en el exterior) (Mujer, 56 años).

"Yo creo que en las dos partes, porque en ambas tengo experiencias alegres y tristes" (Hombre, 45 años).

Para citar este artículo:
Giraldo Z., G. A.; Salazar H., M.; Botero G. P. (julio - diciembre 2012). Migración en Colombia: factores psicosociales y vínculos transnacionales. Ánfora, 19 (33), 51 - 69. Universidad Autónoma de Manizales. ISSN 0121-6538. 
A pesar de que un alto porcentaje manifiesta sentirse mejor en el país de origen, muchos de los que se encuentran radicados fuera quieren permanecer allí, resaltando una mejor calidad de vida, pese a las adversidades que han tenido que afrontar. Esta calidad de vida expresada en mejor vivienda, alimentación, vestuario, por encima de las mismas relaciones afectivas, ya que algunos manifiestan cambios en sus relaciones; sin embargo, prefiere estar allí por sus comodidades materiales.

\section{Aspectos positivos de la migración}

Se considera que, paralelamente con la migración, los emigrantes construyen y extienden el "mito del migrante triunfador", en virtud del cual se minimizan los problemas y se exageran los logros. En este sentido, Puyana et al. (2009), aseguran que "el acto de migrar es bien visto por los familiares como expresión de éxito, idea que también es interiorizada por algunos de los migrantes que en ocasiones sienten que los esfuerzos hechos durante su proceso migratorio han valido la pena por el bienestar alcanzado para ellos y sus familias" (p.108).

Esta idea del "mito triunfador" no sólo estimula la migración de otros familiares (a través de las diferentes redes) sino que hace difícil una valoración más objetiva de los aspectos positivos y negativos de la migración. No obstante, se encontró que la mayoría de las razones expuestas dejan entrever algunos aspectos objetivos y que, por ejemplo, en gran medida se considera la migración como una experiencia positiva cuando se le asocia a la oportunidad y conservación de un empleo:

"Actualmente estoy trabajando y estoy muy bien" (Mujer, 48 años).

"Yo trabajo en un hospital. Además a veces trabajo para la gente que ya salió del hospital. Estamos bien y no nos falta nada" (Mujer, 36 años).

"Que aquí tengo trabajo y le puedo mandar a mi familia para que estén bien y tengo la esperanza que me va a ir siempre mejor" (Mujer, 46 años).

Levitt (2010) sostiene, en este orden de ideas, que los niños y niñas de inmigrantes adquieren contactos y habilidades sociales que son útiles en ambos entornos.

\section{Aspectos negativos de la migración}

Los aspectos negativos o desfavorables de la migración suelen ser de dos tipos: sentimentales y económicos. En los primeros se puede decir que imperan los sentimientos -todavía no superados- de pérdida y ausencia de los seres queridos. "El distanciamiento físico, que corresponde a no verse en largos años. Otra consecuencia es que se pierde el poder de autoridad, ya cada quien es dueño de su propia vida" (Mujer, 56 años).

Se considera también como un aspecto negativo ligado a los sentimientos, la comprobación de la pérdida o transformación -inevitable- de las relaciones afectivas:

"Mis hijos se retiraron mucho de mí; han cambiado, quieren mantener a toda hora donde la abuela" (Mujer, 28 años).

Para citar este artículo:
Giraldo Z., G. A.; Salazar H., M.; Botero G. P. (julio - diciembre 2012). Migración en Colombia: factores psicosociales y vínculos transnacionales. Ánfora, 19 (33), 51 - 69. Universidad Autónoma de Manizales. ISSN 0121-6538. 
En cuanto a los aspectos negativos de tipo económico, sin duda el más común es la frustración por no poder alcanzar las metas soñadas, por el incumplimiento de algún objetivo o por la constatación de que las obligaciones familiares y laborales aumentan o no son debidamente valoradas por los familiares lejanos.

En algunos casos se hace presente el fracaso del proyecto y la profundización de la problemática que se quería solucionar a través de la migración:

"Me la paso, trabajando, haciendo horas en lo que resulte para mantener a mi familia. Pero nada de esto vale la pena, porque el dinero no me ayudará a recuperar el tiempo perdido con mi hijo y con mi abuelo que está enfermo de cáncer. Creo que el mayor error de mi vida fue haberme venido a este puto país" (Mujer, 27 años).

\section{Conclusiones}

Este estudio coincide con muchos de los autores consultados en la percepción general de que la migración es un proceso en el cual predominan las ambivalencias, no solamente entre los propósitos personales y colectivos, sino, especialmente, en las transferencias y desplazamientos de sentidos y emociones (Puyana et al., 2009). Ambivalencias que son visibles en la cesión de ciertas funciones y poderes. Pero también en el manejo, expresión y significado de las emociones más importantes en torno a los procesos vividos. Quizá por esto las respuestas a las entrevistas oscilan entre la idealización máxima del proceso migratorio, por un lado, y, por el otro, la comprensión marcadamente realista y dramática de sus efectos.

Las respuestas analizadas en el presente trabajo confirman la presencia de causas internas y externas en la decisión de migrar. Entre las externas se citan mayoritariamente: la pobreza, la violencia, el desempleo, los bajos ingresos económicos, las enormes responsabilidades familiares, y el abandono conyugal, entre otros. Entre las causas internas se destacan: el sueño de otros horizontes, la ambición de un mejor país, el deseo de aventuras y nuevas formas de vida, la necesidad de reunirse con otros familiares emigrados o de alejarse de una mala situación sentimental, entre otros muchos.

Se confirma también la enorme carga simbólica y motivacional del "sueño migratorio" al interior de las familias. No sólo es un impulso individual el que se pone en juego sino que, como se ha podido comprobar en los estudios más recientes, implica la participación de los imaginarios colectivos y surge de un proyecto familiar común.

En esta misma dirección, se encontró que el apoyo de familiares o amigos representa una motivación de fondo en el proceso migratorio, no solamente en términos económicos sino, además y de forma significativa, en términos de apoyo psicológico y emocional. 
De otro lado, se halló que la mayor parte de los temores de quienes emigran tiene que ver con alcanzar sus principales objetivos o fracasar. Entre los mayores riesgos se citan: la pérdida de la familia y el distanciamiento o la disminución de los afectos primordiales.

$\mathrm{Al}$ analizar en detalle los sentimientos de los emigrantes (antes, durante y después del proceso migratorio) son bastante ambiguos y fluctúan entre el dolor y la alegría extremos. Curiosamente, a estos sentimientos les sigue la idea, más compleja, de "sacrificio" que se convierte, también, en el soporte psicológico y moral del proyecto migratorio y en la meta que justifica cualquier sufrimiento. Eso se debe a la razón del interés colectivo-familiar que el emigrante sufre y supera, al mismo tiempo, las primeras secuelas psicosociales que produce la migración.

Respecto a los cambios en los vínculos (personales, familiares y sociales) del emigrante se dan dos tipos de respuestas radicales: los que se niegan a aceptar los cambios (aduciendo el logro de las metas establecidas) y los que denuncian los principales aspectos negativos de la migración (la distancia y la pérdida de la confianza de los seres queridos).

Nuestro estudio también confirma la cada vez más elevada migración femenina en nuestra región, con las implicaciones de género correspondientes, así como la inevitable realización de nuevos y muy concretos acuerdos internos para el mantenimiento, manejo y protección de los hijos.

No obstante lo anterior, subsiste en las familias transnacionales una percepción que parece contradictoria: la del fortalecimiento de las relaciones familiares como consecuencia de la distancia y del sueño migratorio. Esto quiere decir que no son necesariamente negativas las secuelas de la migración sobre las familias y que, en muchas ocasiones, es el proceso migratorio el que siembra o hace renacer los lazos de afectividad y solidaridad al interior de la familia transnacional.

Sin duda que las consecuencias inmediatas más importante del proceso migratorio tienen que ver con el reordenamiento del poder y el manejo de la autoridad al interior del grupo familiar. En términos generales, quien se queda y maneja los recursos económicos provenientes de la migración es quien termina asumiendo la autoridad y el poder familiar.

Por eso no es extraño que la mayoría de las percepciones familiares sean optimistas y recalquen los valores derivados de esa experiencia: auto-estima, ayuda mutua, solidaridad. En muy pocos casos se habla de experiencia y cambios negativos.

En este estudio se confirmaron tres tendencias en relación con las y los "cuidadores": quienes piensan que las novedades y cambios son de tipo afectivo, quienes creen que los cambios afectan la solución de problemas y quienes piensan que estas noveda-

66 des determinan la toma de decisiones. A pesar de esto, los cuidadores aceptan estas

Para citar este artículo:
Giraldo Z., G. A.; Salazar H., M.; Botero G. P. (julio - diciembre 2012). Migración en Colombia: factores psicosociales y vínculos transnacionales. Ánfora, 19 (33), 51 - 69. Universidad Autónoma de Manizales. ISSN 0121-6538. 
transformaciones como positivas y generadoras de valores más sólidos: la responsabilidad, la tolerancia, la reconciliación y el agradecimiento.

$\mathrm{Al}$ indagar por las tensiones y enfrentamientos que resultan del proceso migratorio, los principales conflictos se relacionan con el manejo de los recursos económicos y la incertidumbre (inestabilidad, miedo, temor) que produce aceptar las nuevas relaciones de autoridad. Este análisis confirmó la tendencia de la familia transnacional a ocultar y reinventar las experiencias y sentimientos e, incluso, a renegociar las tensiones existentes, con el propósito de hacer feliz al otro y mantener el sueño migratorio.

Los resultados de este trabajo concuerdan con la mayoría de investigaciones y especialistas consultados, en cuanto a que los emigrantes y sus familias perciben el proyecto migratorio como algo sumamente positivo. La mirada que tiene la familia transnacional sobre la migración y sobre sus emigrantes es una mirada pragmática, que percibe la migración como una experiencia positiva de cambio y aprendizaje y no, como muchos piensan, como una experiencia indeseable.

Las opiniones respecto al lugar donde se siente mejor el emigrante se muestran bastante divididas. Sin duda que esta percepción está asociada al tiempo de permanencia fuera del país y a la duración misma del proyecto migratorio. Por lo visto hasta el momento, a medida que pasa el tiempo, aumenta la conformidad del emigrante con su lugar de destino.

También se pudo comprobar que la visión optimista que se tiene de la migración en gran parte se sustenta en el "mito del migrante triunfador", según el cual se minimizan los problemas y se exageran los logros para mantener y exaltar los resultados económicos del proyecto. Esta idea no sólo estimula la migración de otros familiares (a través de las diferentes redes) sino que hace difícil una valoración más objetiva de los aspectos positivos y negativos de la migración.

No obstante, la mayoría de los entrevistados considera la migración como una experiencia positiva y está asociada a los siguientes logros: la oportunidad y conservación de un empleo, las posibilidades de superación personal y, en el caso de los hijos de migrantes, las nuevas experiencias y aprendizajes obtenidos.

Los aspectos negativos o desfavorables de la migración suelen ser de dos tipos: sentimentales y económicos. Los primeros, básicamente por la pérdida y ausencia de los seres queridos y la pérdida o transformación -inevitable- de las relaciones afectivas. En cuanto a los aspectos negativos de tipo económico, sin duda el más común es la frustración por no poder alcanzar las metas soñadas. 


\section{Referencias}

Actis, W., Pereda, C. y de Prada, M. (2002). Inmigración, escuela y mercado de trabajo. Una radiografía actualizada. Colección Estudios Sociales (11), Barcelona: La Caixa. Recuperado de: http://www.ucm.es/

Castro C. (2007). Cambios en la autoridad familiar a partir de la migración internacional. Tesis de grado. Pereira: Universidad Tecnológica de Pereira. Facultad Ciencias de la educación, escuela de Ciencias Sociales.

CLACSO (2010). Migraciones, Género, familia y Educación. Consejo latinoamericano de ciencias sociales. Recuperado en: http://www.clacso.net

Daiute, C. y Lightfoot, C. (2004). Narrative Analysis. New York: Sage Publications.

Daiute y Botero (2011). Relatoría en el II encuentro del proyecto colectivo: Narrativas y memoria colectiva. Santiago de Cali: El balcón.

Garay, L. y Medina, M. (2008). La migración colombiana a España. Madrid: Ministerio de Trabajo e Inmigración. Documento en línea: http://extranjeros.mtas.es/es/ObservatorioPermanenteIntegracion/OtrosDocumentos/archivos/21_La_migracion_colombiana_a_Espana.pdf.

Gil, S. (2010). Politicas migratorias, género y vida familiar. Un estudio exploratorio del contexto español. Grupo Interdisciplinario de investigadores migrantes -GIIM-. Obra Social Caja Madrid. Recuperado de: www.giim.files.wordpress.com/

González, L. y Restrepo, J. (2010). Prácticas de continuidad de los vínculos parentales en las familias transnacionales colombianas en España. Revista latinoamericana de Estudios de Familia 2, (enero - diciembre, 2010). 79 - 97. Manizales: Universidad de Caldas.

Hurtado, G., Rodríguez, J., Santamaría, S., Pimentel, B. (2007). Los que se quedan: una experiencia de migrantes. Universidad Autónoma del Estado de Hidalgo. Revista Cientifica Electrónica De Psicología Icsa-Uaeh (6). Recuperado de: http://dgsa.uaeh.edu.mx/revista/psicologia/IMG/pdf/1_-_No._6.pdf.

Levitt, P. (2010). Los desafíos de la vida familiar transnacional. Familias, niños, niñas y jóvenes migrantes. Rompiendo estereotipos. Grupo Interdisciplinario de investigadores migrantes -GIIM- .Obra Social Caja Madrid. Recuperado de: www.giim.files.wordpress.com/

López, L. y Loaiza M. (2009). Padres o madres migrantes internacionales y su familia: Oportunidades y nuevos desafíos. Revista Latinoamericana de Ciencias Sociales, Niñezy Juventud 7, (2 Julio - Diciembre, 2009). 837-860. CINDE - Universidad de Manizales.

OIM (2004). Estudio sobre Migración Internacional y Remesas en Colombia. http://www.oim.org.co/ anexos/documentos/publicaciones/libro88.pdf consultado Julio 2008.

Pedone, C., Gil, C. Retis, J., Echeverry M., Nihil M. y García, M. (2010). Familias, niños, niñas y jóvenes migrantes. Rompiendo estereotipos. Grupo Interdisciplinario de investigadores migrantes -GIIM- .Obra Social Caja Madrid. Documento en línea disponible en: : www.giim. files.wordpress.com/

Para citar este artículo:
Giraldo Z., G. A.; Salazar H., M.; Botero G. P. (julio - diciembre 2012). Migración en Colombia: factores psicosociales y vínculos transnacionales. Ánfora, 19 (33), 51 - 69. Universidad Autónoma de Manizales. ISSN 0121-6538. 
Pesantez, B. (2006). Las redes familiares en el proceso migratorio de los ecuatorianos a España. Centro de Estudios Sociales y Politicos Latinoamericanos.-CESPLA. Universidad de Cuenca (Ecuador). Recuperado de: www.rua.ua.Es/

Puyana, Y., Motoa, A. y Viviel, A. (2009). Entre aquí y allá: las familias colombianas transnacionales. Bogotá: Fundación Esperanza. 